\title{
Sexual Identity Among Men Who Have Sex with Men in Shanghai
}

Sun Zhongxin, James Farrer and Kyung-hee Choi

\section{(2) OpenEdition \\ 12 Journals}

\section{Electronic version}

URL: https://journals.openedition.org/chinaperspectives/598

DOI: 10.4000/chinaperspectives. 598

ISSN: 1996-4617

\section{Publisher}

Centre d'étude français sur la Chine contemporaine

\section{Printed version}

Date of publication: 1 April 2006

ISSN: 2070-3449

\section{Electronic reference}

Sun Zhongxin, James Farrer and Kyung-hee Choi, "Sexual Identity Among Men Who Have Sex with Men in Shanghai", China Perspectives [Online], 64 | march - april 2006, Online since 21 December 2006 connection on 21 September 2021. URL: http://journals.openedition.org/chinaperspectives/598 ; DOI: https://doi.org/10.4000/chinaperspectives.598

This text was automatically generated on 21 September 2021.

(C) All rights reserved 


\title{
Sexual Identity Among Men Who Have Sex with Men in Shanghai
}

\author{
Sun Zhongxin, James Farrer and Kyung-hee Choi
}

\section{EDITOR'S NOTE}

This research was supported by NIMH Center Grant No. MH42459 (Center for AIDS Prevention Studies) and Japanese Foundation for AIDS Prevention.

1 Although homosexual practices were largely tolerated in classical Chinese society, after 1949, under the People's Republic homosexuality has been regarded as "hooliganism". During the Cultural Revolution homosexuals were classified as "bad elements", along with landlords, rich peasants, counterrevolutionaries and "rightists". In the 1980s and 1990s, gays were easy targets for police and security authorities, and became sacrificial lambs to the broader goals of government and society ${ }^{1}$.

2 The 1980s witnessed small breaks in the taboo on public discussion of homosexuality, and a few journalists and scholars started writing articles and books on homosexuality at that time, though much of this literature was from a medical or mental health perspective in which "treatment" or "prevention" of homosexuality was still the aim². Increased indigenous writing about gays and increased media exposure to global and Asian regional gay rights movements led to great changes in the popular understandings and legal treatment of homosexuality in the 1990s. The label of hooliganism under the old Criminal Law, which included sodomy, was abolished in 1997, and in 2001 the Chinese Psychiatry Association removed homosexuality from its list of mental disorders. In 2003, public discussion of homosexuality entered the university curricula in mainland China $^{3}$ and received positive feedback from the mainstream mass media and society. However, even with the changing of legal regulations and increasing openness, homosexuals as a group still felt misunderstood and discriminated against. 
3 In general, discussions of non-marital sexuality became popular in magazines, radio and television programmes in the 1990s, creating a more accepting climate for alternative sexual stories ${ }^{4}$. And in this climate it is becoming possible for the first time in modern mainland China for a large number of men to identify themselves as homosexual within limited public and private spheres. More and more young people are now able to identify their same-sex sexual desires using identity discourses borrowed from the public sphere or private conversations in a gay community. Within this relatively new context it is important to ask how a number of ordinary Chinese identify or label their sexual orientation, what the processes are by which they come to decide on an identification of same-sex sexual desire, and how they share these identities within their everyday social networks.

Chinese gay identity terms in the public sphere

4 "Homosexual" or "gay" are Western words translated into Chinese. According to Zhang Beichuan, homosexuality was translated into tonglian'ai in 1920, and subsequently became tongxinglian, but since 1981 tongxinglian has reappeared in some medical books and other translated materials in China ${ }^{5}$. For Zhang Beichuan, "male homosexuals", "gay", and "gay men" are the modern words to refer to this group of men.

5 At the same time, the other important researcher in this field, Chinese Academy of Social Sciences sociologist Li Yinhe, used tongxinglian instead of tongxing'ai, as in some of her books ${ }^{6}$. On the other hand, many authors choose to borrow the Chinese term tongzhi (comrades). This term has appeared in such books as those written by Hong Kong sociologist Zhou Huashan ${ }^{7}$. Zhou argued that tongxing'ai or tongxinglian are the labels structured by hetero-centric hegemonists, and their use will harm the tongzhi communities and the tongzhi movement ${ }^{8}$. Tongzhi has also gained wide acceptance among overseas Chinese communities (including Hong Kong and Taiwan) and movements targeting gay rights in China ${ }^{9}$.

6 As in the West, the AIDS crisis provided a major impetus for the tongzhi movement in China. In order to succeed in AIDS prevention, government organisations and NGOs began reaching out to men who have sex with men. The acronym MSM, "men who have sex with men", has been used to refer to this group in the West since the mid-1990s and is now being widely used among those conducting AIDS/STD or risk behaviour research in China. The concept of MSM is different from that of male homosexuals, as MSM is based upon sexual behaviour rather than sexual orientation. It includes male homosexuals and male heterosexuals who have sex with men, even though the majority of this MSM group are still considered male homosexuals by the public. During recent years, MSM or homosexual issues have been receiving social recognition from the media. However, strongly associating gay issues with the AIDS crisis might also stigmatise entire communities and heighten discrimination against them.

Self-identification among gay men in China

7 Even though publications on homosexuality are on the increase, most are "stories" with some analysis. Scholars are still at the stage of "searching for" homosexuals in China ${ }^{10}$. Aiming their writing at a general heterosexual public doubting even the existence of homosexuals in China, these pioneering authors understandably focus on "discovering" and "uncovering" the existence of homosexuals in China rather than on the processes of self-discovery and self-disclosure of homosexuals themselves. 
8 Popular ethnographic literature on homosexuality in China emphasised the hidden or forbidden nature of gay relationships in China and the pressures to conform to the norms of a hetero-normative patriarchal society in which marriage is expected. As Li Yinhe writes, the main difference between Western and Chinese homosexual men is the strong pressure to marry in China ${ }^{11}$. More recent research has focused on the gay subcultures emerging in China in which self-revelation is possible within a limited circle ${ }^{12}$. However, especially since the advent of the internet, urban Chinese attitudes toward sexuality are rapidly changing. There are frequent reports on homosexuality in online media, and many "straight" urban Chinese have adopted a more accepting attitude towards homosexuality. Though men still face many of the social pressures described by Li Yinhe, some gay men in cities such as Shanghai now are able to "come out" at work or to selected not-gay friends, classmates and co-workers.

Research in the United States shows that gay men often do not reveal their sexual identity to outsiders out of a fear of persecution, discrimination and rejection. However, studies also show that men have higher self-esteem and a more coherent social and personal identity if they are able to disclose aspects of their sexual identity to a wide range of people in their social circle ${ }^{13}$. At the same time, we should not draw a simply dichotomy between those who are "out" and those who are hiding their sexual identity. As Eve Kosovsky points out, even gays and lesbians who are "out" must continue managing issues of sexual disclosure in social interactions throughout their lives $^{14}$. In the classic model of gay identity development, Vivienne Cass describes six stages beginning with "identity confusion" and ending in "identity pride" and "identity synthesis" 15 . While this model is clearly teleological and based on a Western definition of self acceptance and social engagement, self-disclosure has significant outcomes for gay men in China as in the West. Men who conceal their sexual identify may experience emotional distress, and coming out may be linked to a reduction in such distress ${ }^{16}$. Implicit in the discussion of "coming out" is a general insight into the importance of self-disclosure for building social ties. Research on self-disclosure shows that revealing personal information is useful in building social ties and obtaining social support that might not be available without the sharing of intimate details. Socially mediated benefits associated with self-disclosure to a confidant include esteem support, information support, and motivational support ${ }^{17}$.

10 A quantitative study of gay men's coming out experiences in Hong Kong found that men were more likely to disclose their gay identity to gay friends than to straight friends, and to straight friends and siblings rather than parents. The authors argue that it may be particularly difficult for men in Chinese societies to disclose gay identity to their parents because of patriarchal family norms associated with Confucianism. Men who came out and established ties to the gay community reported lower levels of psychological distress ${ }^{18}$. This study was limited, however, to men who had already "come out", a group that may be less common in mainland Chinese cities such as Shanghai. Moreover, some Western researchers argue that Western notions of "coming out" and sexual identity should not be applied to Chinese societies, and that we must be aware of local patterns of self-identification and local markers of sexual and social distinction ${ }^{19}$.

11 Our qualitative study aims to describe various patterns of sexual self disclosure among men in Shanghai. We first describe the terms MSM in Shanghai use to define a same-sex identity. Through this we consider whether there is a single definitive conception of 
gay identity among MSM. We then examine the stories by which men define their own sexual identity. We can ask at what stage in life Chinese men first come to see themselves as sexually interested in men, and what resources they use in arriving at these identifications. We then look at the ways in which men manage these sexual identities in different social contexts as adults, and what contexts these strategies have for them.

Data and methods

12 A sample of 30 MSM in Shanghai was recruited between December 2003 and June 2004 through informal social networks. We first contacted gatekeepers of Shanghai's MSM community who volunteered for the Shanghai Hotline for Sexual Minorities, which provide gay- and HIV-related services to MSM and asked them to refer to us potential participants. Men were eligible for the study if they were 18 years old or older, lived in Shanghai, and had same-gender sex. Eligible men were offered RMB50 (US\$6.50) as an incentive for participation.

Participants provided informed consent and were interviewed face-to-face in Mandarin or the Shanghainese dialect using a semi-structured interview guide. The interview guide asked seven broad topics: participants' migration experiences, their life in general, social networks of friends or important individuals, meeting venues that they frequent, sexual partnerships, experiences with condoms, and coming out as gay. Four interviewers were trained to conduct in-depth interviews. Each interview lasted approximately two hours and was audio-taped. All study procedures were approved by the institutional review boards of Fudan University, Shanghai, China and the University of California, San Francisco, California. The audio-taped interviews were transcribed verbatim in Chinese. Data analysis was based on answers coded topically and answers grouped according to thematic similarity using the method of excerpt files of quotes. The final data analysis involved selecting quotes that represent the points of view of the largest groups of quotes.

Findings

The first section of findings briefly outlines the types of terms respondents used to describe their sexual identity. The second section summarises the types of narratives of how respondents came to understand their own sexual orientation. The third section describes how these men represent their identity differently in various social circles.

Terms of self-identification

When asked how they identified or described their sexual identity, interviewees used a variety of terms. The most common term in use among the interviews was the term tongzhi, literally "comrade". Some preferred this term because it didn't have such obvious sexual connotations, nor did it sound foreign like the term "gay". As one respondent said: "I like the term tongzhi..., it is not too foreign sounding, nor is too much in your face" (Interview 19). Terms such as "homosexual" might be considered to have negative connotations because of their association with the quasi-criminalisation and medicalisation of homosexuality in the recent past in China. Still, these terms are inescapable. One respondent explained: "Just like my gender, the term tongxinglian has become a part of my body, part of my essential nature, but I really don't know what term I should use to describe myself. I feel that traditional terms like 'homosexual' all have a derogatory connotation, and I can't accept them. In comparison, the term tongzhi is better". 
16 Another way of describing gay identity focused more on membership in the tongzhi community. The term tongzhi has this connotation, but one could describe oneself as simply being "in the circle" (quannei), referring to the "tongzhi circle" (tongzhiquan) : "I like to use the term 'someone in the circle' to describe myself. Other terms make me uncomfortable. People with this kind of behaviour can just use the term quannei, and this will let others know" (Interview 15). For this respondent, being "in the circle" had the connotation of being in a secretive and closed circle.

These arguments for the term tongzhi or quannei seem more common among men associated with the active tongzhi community establishing itself in Shanghai. Many respondents we interviewed preferred other terms. For instance, several men preferred the English word "gay": "I like to use the term 'gay'. Online I will say that I am 'g'. Everyone will understand. These other terms, tongzhi and tongxinglian are too crude" (Interview 14).

18 As one respondent explained, the advantage of the term "gay" (or the single letter "g") was that many straight people might not know what it meant, whereas they would all know the term tongxinglian (Interview 1). As a foreign term, it also might seem more classy and less crude than standard or colloquial Chinese terms. One respondent also associated the term "gay" with a more upbeat and less sexualised social identity : "I like to use the term 'gay' to describe myself, because it is not so cold. Like being together and appreciating one another, enjoying this kind of life, not just having sex" (Interview 20).

19 We initially suspected that men who are part of the international gay scene in Shanghai might be more likely to use the term "gay", but in fact, none of the respondents quoted above were associated with this scene. Most had no contact with foreign men. Rather the use of the terms "tongzhi" and "gay" seems vaguely (and inconsistently) related to a more politicised and blunt presentation of self as tongzhi versus a more oblique and stylish presentation of a male sexual orientation involved in the foreign term "gay".

20 A few respondents, especially older respondents who were not so much part of the social circle of gay men in Shanghai still preferred the term tongxinglian, which has been in use for much longer and is still the preferred term in straight society and in the media. This use of tongxinglian is illustrated by an older married respondent with only recent contact with a larger gay community: "I suppose I must be tongxinglian. I got married because I reached the right age and I had to get married. Back then there was not so much information, so I didn't know there were so many others like this...We knew nothing about tongzhi back then, we just knew that we liked a certain classmate and so on. I did see an article in the newspaper about it, but I couldn't find this group of people. Now I can use the internet to find them" (Interview 28).

21 Many men described the internet in particular as the first place that they learned of terms like tongzhi or came to have a positive identity as tongxinglian, a term that had negative connotations from the early reform era. In addition to implying a more mainstream orientation, the use of the term tongxinglian seems to mark the user as somewhat outside the circle of tongzhi.

22 Another identity labelling issue involves distinctions between men who have sex only with men and those who also have sex with women. For example, one respondent described himself a "pure tongzhi" (Interview 6), meaning a person who only has sexual interest in men. Another respondent used the term "pure gay" to describe himself. Like 
the term "pure tongzhi", it implied an absolute rejection of sex with women. For one respondent, it even implied a rejection of men who had sex with women : "Making love to a woman is disgusting to me, so I can't go out and make love with one of those men who is not gay... I am a pure gay and I want to find a man who is also a pure gay" (Interview 1).

Not everyone we interviewed accepted the view of themselves as homosexual. Sex workers, known as "money boys", might completely deny any personal sexual interest in men. The money boys we interviewed came from the countryside and did not have a high level of education. Most do not view themselves as homosexuals even though most of their clients are men. Selling sex may first of all be a social practice motivated largely by economic reasons. As Travis Kong argued in his research report on the sexual politics of Chinese male sex workers, sex work involves a worker performing sexual acts that might not necessarily conform with his personal sexual interest ${ }^{20}$.One said simply : "I am not homosexual, I only go with men for money" (Interview 21).

On the other hand, in his contact with clients at work this respondent had to feign sexual interest in men, in a sense reversing the tendency of homosexual men to hide their sexual interests in everyday work relationships. In contrast, another respondent who also had sex with numerous female partners said that he was bisexual (shuangxinglian). He also said: "I can describe myself as gay" (Interview 22). The term "gay", like tongzhi, thus could have flexible meanings within this broad spectrum of male-male sexual desire. This might be one reason why some men insisted on using the term "pure gay" or "pure tongzhi" to distinguish themselves from men who might be bisexual or married.

Identifying oneself as a man who desires men

Excepting the two respondents who identified themselves as straight (both commercial sex workers), almost all gay or bisexual respondents reported becoming aware of a same-sex sexual desire at ages ranging from 5 years old to 20 years old $^{21}$. Most respondents reported noticing a sexual attraction to men during puberty or earlier, well before their first sexual experiences with men. Many respondents did not have their first sexual experiences with men until early adulthood, or even early middle-age. Sexual partners then often introduced them to a larger circle of gay friends. For instance, the following respondent described having sex unexpectedly at the age of 18 : "At the age of 13 or 14 I first realised my sexual orientation was different from other males. Back then when I saw pictures of men, I felt aroused. I was quite confused, and also curious. Back then I had no idea what tongzhi were or what it meant, I was still young, still studying. I didn't think too much about this kind of thing... At the age of 16-17, I saw a guy jerking off in the bathroom, and I became aroused. So he suggested we masturbate each another" (Interview 6).

26 A few respondents described their initial recognition of sexual interest in other men beginning with their sexual initiation, usually by an older man. One respondent described being "brought into" the gay life, by a teacher at a sports academy where he was a boarding student: "The first time I understood all this, it was my coach, also my headroom teacher, who 'brought me in'. I was 17. One time in the shower room, all of us kids were just fooling around, punching each other. Then this coach came up. Most of the others left, but I just stayed around. He was in the bath tub, and I was in the shower. He asked me : 'are you clean yet ?' I said : 'I am already finished, ready to go'. He said : 'I can see that you are not yet really clean'. And he started helping me bathe. 
Then he embraced me, giving me a sense of fun, but also a kind of fatherly caring. At that time I didn't understand anything" (Interview 12).

Later the coach invited him to share a dorm room with him because the dorm he was staying in was "too crowded". They eventually began engaging in sexual intercourse. He said that at first he had a hard time accepting his sexual orientation, and even thought about suicide because of social prejudices against gays. Later, he said, he realised that he would be even less happy had he not discovered the gay world. "The most important thing is that I recognised my orientation. The only thing that's difficult now is that I can't find a suitable male partner" (Interview 12).

Whether respondents first became aware of their sexual orientation and then found sex partners (the most common pattern among these respondents), or first found sex partners and then became aware of their interest in men, most of them describe initial discomfort and confusion with their gay identities, the stage Cass describes as "identity confusion" 2 . Almost all of them used words such as "confusion" or "not understanding" to describe this. They also harboured negative judgements about themselves-that they were "abnormal" or suffering from a "moral problem". According to their interview narratives, most of them arrived at an acceptance of being homosexual, or a more positive understanding of their sexual orientation, the stages Cass describes as "identity tolerance" and then "identity acceptance". Given the negative perception of homosexuality in mainstream Chinese society, identity acceptance seems to be mediated by access to specialised information and specialised social resources. For the younger men in particular, the internet has been the most important site not only for meeting other gay men, but also learning a more positive model for gay identity. Chinese internet sites specialising in gay issues offer social and intellectual resources for constructing a positive self identity.

Some men still express negative attitudes towards being gay. The most common problem was a generally negative perception of the personal and sexual ethics of other men in the gay circles they were part of. As the respondent quoted above said, the most common complaint was that they could not find a "good man". In particular it was considered difficult to find a long-term boyfriend. This negative image of the gay community, however, was often balanced out by more positive perceptions of particular gay friends and acquaintances. Some men had more negative perceptions of their own sexual orientation. One married gay respondent said: "This is a natural mistake of the DNA. You can't change it, you can only try to improve the quality of your own life. God was not fair to me. I am damaged goods. It is a tragedy. If I am reborn, I want to be a real man" (Interview 26).

Although this man had a successful career as a government cadre, and then a businessman, his sexual orientation seems to have brought him personal costs. In particular, he feels guilty towards his wife, who he sexually and emotionally ignored. Because he first had sex with men when he was 31 and has lived at the margin of the gay community, he also may have experienced more sexual frustrations than many other men in this sample. He also experiences the difficulties most gay men experience in managing their sexual identity in public roles. This is the subject of the next section. Managing gay sexual identity in different social contexts

31 Our respondents described a range of patterns of dealing with a homosexual sexual identity in interactions with different types of social circles. It is important to consider 
each of these types of social circles separately when understanding the management of sexual identity in Chinese society.

Natal family

As Wong and Tang report in Hong Kong, Confucian family norms make coming out to family members difficult if not impossible for Chinese homosexual men ${ }^{23}$. Respondents said there was "no reason" to let parents know, or that it would give them too much "suffering", or that they would be "unable to accept it". Only three of our respondents have told their parents about their gay identity. One said, "My mother cried three days and three nights. Then she accepted it" (Interview 11). Two other respondents had come out to other family members, but not to their parents. More typically respondents had only hinted at their gay identities to family members, hoping for a gradual or only tacit acceptance. For instance, one left a copy of a book about homosexuality for his mother to read. Usually such attempts to bring up homosexuality in an indirect fashion met with denial or incomprehension by parents. On the other, such indirect strategies seemed to help these men establish a larger space for maintaining their own gay identity when dealing with family members.

In keeping with Confucian ideals, many respondents emphasised the suffering that coming out would bring to their parents, not to themselves. One respondent, a graduate student in a prestigious Chinese university, identified very strongly with the gay movement and felt that he should tell his parents. However, he did not frame his decision as a break with traditional family ethics, but rather as an extension of family values: "I told my family when I was 26 . I believe that family members should have mutual trust, respect and support. I should believe that they will eventually support me. Their first reaction was surprise and a lack of acceptance. But I gradually educated them and they accepted it" (Interview 16).

Like other respondents he also emphasised the importance of family in his life. "No matter what I will consider their ideas and their standpoint..., but they can't influence me as to whether I like men or I like women" (Interview 16). In the end, he feels that coming out helped his relationship with his parents.

As Li Yinhe reports the biggest problem for many gay men was marriage. Many respondents still report strong expectations that they will marry. These expectations are strongest when dealing with family, as one migrant from a small town in China explains : "My gay friends all know about my sexual orientation. No one else knows. I can't let anyone else know. There is no advantage in letting them know. The people where I work certainly don't know..... My family members can't find out. My family members are Buddhists. Their views are very traditional. They couldn't accept homosexuality. If I let my mother know, she would scold me to death" (Interview 29).

On the other hand, other respondents had a less severe sense of these family pressures. And some felt they could avoid the issue. A college student from Shanghai said: "I never talk about these problems (marriage) with my family. However, it has got to the point that I really have to talk about it. The main thing is that I am independent. At the very worst, I can always just keep hiding it from them. Anyway, there are many people now who don't marry at all, or marry very late" (Interview 30).

Equally important in their stories was a sense of women's sexual rights and women's rights more generally. Many respondents said that they had to think not only of their 
family pressures, but the damage that marriage would do to a woman who married them. Most were aware that marriage to a gay man was unacceptable for women.

In sum, respondents were still unlikely to come out to parents about their homosexuality or sexual relations with men for fear of lack of acceptance, but also for fear of hurting their parents. And those who did come out were likely to frame their decision not as a rejection of family and family values, but as an attempt to gain greater acceptance by the family and to extend traditional family values to include a homosexual son. Finally, men still felt great pressures to marry, but some were beginning to see staying single as a viable alternative.

Conjugal family

The majority of our respondents saw heterosexual marriage as incompatible with homosexuality. Many single men hoped to resist family pressure to marry. This represents an increasing identification with the idea of a stable homosexual sexual identity, and also a recognition of the sexual rights of women in marriage. Many respondents said that to get married would be to ruin a woman's life. However, in keeping with patterns discussed by Li Yinhe in the 1990s (1998), three of our respondents were married and two had been married but were now divorced.

Married respondents often described an estranged relationship with their wives, and those who were married usually hid their sexual relationships with men from their wives. One man used a chance to take up a new job in Shanghai as a way of escaping from his marriage. "It was last Chinese New Year when I finally told her. There was a reunion of her old classmates and they all asked her why she picked me out of all the boys who were chasing her. Now I don't come home very often, and I don't show her any affection at home. That made her feel really bad. When I came back home this time, she seemed angry at me. I finally sat her down and told her seriously that I was homosexual. Actually, she should have already guessed. I hadn't touched her for years [since she got pregnant]. She had two choices, to continue this way, or to get divorced. She always chose the former. My son, he probably has already guessed. He always sees me with these handsome guys" (Interview 26). This respondent has a relatively high income, and provides for his son, giving his wife an incentive to stay in the marriage.

While marital relationships were characterised by unhappiness, lack of communication, guilt and misgivings, respondents were much more positive about relationships with their children from these marriages. One described his 13 year-old daughter as "the most important person in my life" (Interview 15). After his divorce, she lived together with him and a boyfriend, whom this respondent described to his daughter as a friend and he treats as a "younger brother". He said that she was getting older, and had accepted this man because he was good around the house. He hasn't told her about their relationship and avoids showing much physical affection in front of her : "In front of my daughter, I must still act like a proper father. I won't be too intimate with him. But behind her back, I will do the work of comforting him. If she understands naturally in due course that is a good thing, but if she doesn't understand, I wouldn't initiate the conversation" (Interview 15).

In general, gay respondents were more likely to trust that their children would accept their homosexuality than their own parents would. Parents have more authority and power with children, and gay men are thus more comfortable with children than with parents.

The straight world 
43 Almost all respondents found it necessary to conceal their gay identity among their ordinary straight friends. The confessions of the few who had tried to come out to straight friends were sometimes met with incredulity or offers to take them to a psychiatrist or doctor. One said he told two of his straight classmates but "they wouldn't believe me. If they believed me, I guess they would be supportive" (Interview 14). Some respondents come out to their straight friends in ambiguous or humorous ways. This partial coming out seems a way of testing the ground both for the reactions of the friends and their own ability to deal with a public gay identity. For one respondent this took the form of giving out information about homosexuality without necessarily talking about his own personal experiences (Interview 5). Another respondent came out to his dorm mates in the university more directly. "When I am on the internet looking at gay pictures, or watching gay movies, my roommates can walk right by and see, and they will understand (that I am gay)" (Interview 25).

Only a few interviewees have open communication about their gay sexual relationships with straight friends. One respondent said: "I have some straight friends who know I am gay. I can talk to them about some (gay) topics, and they are happy to listen. They treat it like a story. They involve themselves in the conversation and don't try to stop me talking about these things. They will ask me about myself, like have you got a boyfriend, have you done this or that lately, stuff like that" (Interview 1).

In general, higher status respondents such as managers and graduate students had an easier time revealing their sexual identity within their straight circles. Migrants, sex workers and respondents with few economic resources were not only less likely to come out to straight friends about their sexual interests in men. Indeed they were less likely to have strong social connections at all. Their lack of social capital made them more careful about managing their public sexual identities. The most general finding was the pattern of avoiding sexual self-disclosure to straight friends. Given that some general talk about romantic and familial relationships is relatively common among straight Chinese men, especially close friends, this lack of intimate self-disclosure tended to erode ties to straight friends.

Several respondents described a tendency to socialise less and less with straight friends as they became more a part of a gay circle. The need to hide their homosexual relations from their straight friends leads to a weakening of these relationships. Many limited their intimacy with straight friends to practical and everyday matters. As one respondent said, "Straight friends will always ask you if you have a girlfriend, so it is more relaxing to go out with gay friends" (Interview 1). Another said: "I have less and less contact with my straight friends. It is not that I don't want to go out with them. It is that I don't want to see them. They will often call me to go out, and I will feel guilty for not going. In the past I wasn't like that, but I have just gotten to be that way over time. So I don't see them so much" (Interview 17).

In sum, a minority of respondents had had relatively successful experiences revealing their gay relationships and identities to straight friends, classmates or co-workers. Some men reported negative reactions or incredulity, but others found they were able to expand their personal zone of comfortable self-expression to include gay friends. On the other hand, other respondents found themselves pushing straight friends to a comfortable distance, expanding their zone of comfort by expanding their contact with other gay men. In both cases the goal was to create a space in which one did not have to practice self-concealment or pretend to be heterosexual. On the other hand, not 
disclosing details of one's personal life to straight friends meant a weakening of those ties in the long term, and this can be seen as a social cost of non self-disclosure.

The tongzhi circle

Almost all respondents reported that conversations and interaction regarding sexual and intimate life were completely confined to the gay circle. For example, one respondent said: "I communicate with friends in the [tongzhi] circle nearly everyday, with other friends its about once a week.... The types of topics we talk about are very different. With ordinary friends, it's just small talk, like how have you been lately. It won't be very deep. With friends in the circle, we can go straight to the point, like how has your sex life been lately, good or bad, or ask if you are getting on with your boyfriend lately. With friends in the circle there is basically nothing I can't talk about (Interview 6).

Another respondent described the gay circle as a separate space in which one could express one's true self: "In the gay circle, everybody knows everybody, so if you want to laugh, you laugh, if you want to walk a certain way, you walk a certain way. It's like returning to a world that belongs to you" (Interview 9).

Gay circles have by far the greatest communication about sexual matters and thus a greater influence on sexual behaviour and sexual risk behaviour, including norms of condom use and norms about multiple partnerships. Gay circles are also the space where men develop a positive sense of their sexual and social identity as gay men.

Participation in various tongzhi circles also has negative social connotations for many of our respondents. Respondents complained that gay men were gossipy, or men in the circle were only after money or only after sex. Some respondents distinguished their small circle of very close gay friends, whom they felt they could rely upon, from a larger gay circle which they described as fickle and phoney. Most commonly men complained that the permissive sexual atmosphere in the gay circle made it difficult to start or sustain an exclusive long-term relationships. One 23 year-old waiter said : "I still don't have a steady boyfriend. In this circle it is hard to find a steady boyfriend. In the circle people don't seem to emphasise feelings" (Interview 29).

There was also mistrust across ethnic lines. Shanghai men complained that nonShanghainese men were likely to want money for sex or even to engage in extortion after having sex. Most non-Shanghai men complained of prejudice from Shanghai men. Because of this mutual mistrust, most gay migrant labourers had fewer chances to build mutual supportive and communicative ties with local Shanghai men in the gay circle.

Although in most cases men were open about their sexual interest in men to their sexual partners, they were not necessarily open about their sexual histories and identities to all their sex partners. The most consistent pattern of non-self-disclosure involved female sex partners. None of the men revealed their sexual relations with female partners to their male homosexual partners. Men with female partners included sex workers ("money boys"), most of whom claimed to be heterosexual, bisexual men with female and male partners, and married men who still had sexual relations with their wives.

Based on such a small sample we can only make tentative conclusions about the identity-forming practices of MSM in Shanghai. However, some patterns clearly deserve more attention. First of all, our findings indicate that there is no single accepted term for identifying a male homosexual sexual orientation among MSM in 
Shanghai. Men use a variety of terms, primarily tongzhi, gay, quanneiren and tongxinglian. MSM use these naming terms them to hide their sexual identity from people outside the gay community. For example, only more sophisticated outsiders will know the meanings of the terms "tongzhi" or "gay", so using these terms may offer some anonymity in social interactions. Men also make use of these different terms to indicate affiliations with one another and to make distinctions within the gay community. Some respondents also use terms such as "gay" to indicate an aspiration to a classy type of lifestyle, or "pure gay" or "pure tongzhi" to communicate distinctions with sexual lifestyles they want to distance themselves from, such as bisexuality or cohabitation with a woman. They make frequent distinctions between men from Shanghai itself and migrants. In sum, these identity naming practices are tactical and political in nature, but clearly not politicised to the extent that terms such as "gay" or " tongzhi" indicate affiliations to distinct well-organised groups. The Shanghai gay community is neither public enough nor organised enough to have created such clear subcultures.

Second, MSM in Shanghai that we interviewed generally have a strong sense of an innate or deeply ingrained sexual orientation. Most report coming to understand that they were sexually interested in men in early adolescence. A positive understanding of oneself as a gay man usually came somewhat later through contact with gay men, and most importantly contact with gay media. Here the internet was of paramount importance. In China there are virtually no print media dedicated to gay or homosexual themes, and those that do exist have very low availability. With over 300 websites dedicated to gay subjects, the internet has a great deal of accessible material. Most men reported coming to understand their sexual identity positively only after contact with writings on the internet on homosexuality. Although less dramatic than the recent growth of the internet there are also increasing social and physical spaces for the development of a gay identity in Shanghai. There are several gay bars, a gay dance club, public baths and saunas, parks and public cruising spots. In addition we have to think of the increasing status divides reproduced in these spaces, with expensive Westernstyle bars catering to a Westernised professional elite, working-class men congregating in other spaces such as dance halls, and migrants congregating mostly in "free" spaces such as People's Square.

Finally, MSM in Shanghai still express reluctance to reveal their sexual identity beyond the circle of gay friends. This means also that the gay circle is an important source of support for these friends. Some men do come out to family members and straight friends, co-workers and classmates. These men report some negative reactions (incomprehension, or advice to seek medical treatment), but largely have supportive reactions. An important dynamic involves variations in social status and social power. Men with higher social and economic capital (good jobs and/or good education qualifications) seem more able to reveal their sexual identities to straight friends. Similarly, men were less worried about revealing their sexual status to their own children than to their own parents. In both cases it seems that social status, power and control of resources allow the men to gain more easy acceptance from others, whether friends or family members. Men with weak social ties, such as migrant workers, feel more constrained in their self-revelation. The ability to "come out", therefore, seems to depend on access to social resources. 

benefits of coming out to various groups. For instance, some men in government organisations reported that coming out would damage their reputations. In general men feel constrained by perceived discrimination against homosexuality from coming out to straight friends. Most gay men report hiding their gay identity from straight friends, but they also report dissatisfaction and frustration with these practices of hiding sexual identity. Hiding sexual identity also has costs. A perceived benefit from coming out is the ability to maintain closer and more intimate ties with straight friends and family. As gay men build social ties to other gay men, they often report an increasing degree of social separation from non-gay friends. Furthermore, among straight men a complete lack of self-disclosure about romantic and sexual behaviour can be interpreted as social distance. Non self-disclosure and retreat into a gay circle of intimate friends thus can lead to a weakening of social ties with non-gay friends, and a consequent loss of social capital. Chinese men, whether gay or straight, place high value on informal social connections, colloquially known as guanxi. So the costs of social withdrawal and isolation could be higher than for Western men.

One of the most important issues for gay men in China is the problem of marriage. Here we sense some signs of change. While most men experience pressures to marry, many men feel that they may be able to avoid marriage. Respondents' statements point to recent social changes that will make it easier for gay men to avoid pressures to marry. These include late marriage, increasing rates of non-marriage, married people who do not have children and the increasing acceptability of pre-marital sex. Less directly related to marriage, but providing a greater space for alternative lifestyles, are trends toward renting an apartment on one's own before marriage and the ease of moving to other cities to work and live. All these trends make it possible to live a life as a "single" man while not directly challenging parents over the issue of marriage or homosexuality.

Equally important are general changes in sexual culture in China. The acceptance of homosexuality is part of a much larger liberalisation of sexual attitudes more generally, including an increased permissiveness about non-marital and non-reproductive sex ${ }^{24}$. There is also an increased emphasis on women's sexual rights. For most men, the strongest argument against marriage was the violation of a woman's right to a healthy sexual life. We thus have to consider changes in attitudes toward homosexuality in the context of changes in attitudes towards sexuality generally.

\section{NOTES}

1. Robert Geyer, "In Love and Gay," in Perry Link, Richard P. Madsen, Paul G. Pickowicz, Popular China : Unofficial Culture in a Globalizing Society, Lanham, Maryland, Rowman and Littlefield, 2002, pp. 262-263.

2. For example, proof can be found in some recent mainstream psychology textbooks and psychological consulting practices.

China Perspectives, 64 | march - april 2006 
3. Funded by Chi Heng Foundation. In 2003, Fudan University started a course "Homosexuality, Health and Social Science" (Tongxinglian jiankang shehui kexu) for graduate students, by the School of Public Health of Fudan. And in autumn 2005, Fudan University started a general education credit course "Lesbian and Gay Studies" (Tongxinglian yanjiu) for undergraduate students, in the Department of Sociology within the School of Social Development and Public Policy.

4. See James Farrer, Opening Up : Youth Sex Culture and Market Reform in Shanghai, Chicago, University of Chicago Press, 2002.

5. Zhang Beichuan, Tongxing'ai, Jinan, Shandong kexue jishu chubanshe, 1994.

6. Li Yinhe, Tongxinglian yawenhua (The Subculture of Homosexuality), Beijing, Jinri Zhongguo chubanshe, 1998. This book is a revised version of Li Yinhe and Wang Xiaobo, Tamende shijie : Zhongguo nan tongxinglian qunluo toushi, Hong Kong, Tiandi tushu youxian gongsi, 1992.

7. Zhou Huashan, Beijing tongzhi gushi (Stories of Beijing Comrades), Hong Kong, Comrade Research Society, 1996, or Zhou Huashan, Tongzhi lun (On Tongzhi), Hong Kong, Comrade Research Society, 1997, and Zhou Huashan, Hou zhimin tongzhi (Postcolonial Tongzhi), Hong Kong, Comrade Research Society, 1998.

8. Zhou Huashan, Tongzhi lun, p. 362.

9. An example is John Loo (ed.), A New Reader on Chinese Tongzhi (Essays \& Conference Proceedings), Hong Kong, Worldson Publications, 1999, or its Chinese version : Lu Jianxiong (ed.), Huaren tongzhi xin duben (A New Reader on Chinese Tongzhi), from a Chinese-hosted global conference.

10. Included in this category of writing are Li Yinhe's book (Tongxinglian yawenhua, op. cit), those of Zhou Huashan (Beijing tongzhi gushi, Hou zhimin tongzhi, op. cit.), and other books such as Chen Liyong, Zhongguo tongxinglian diaocha (Survey on Chinese Homosexuals), Hong Kong, Tianma tushu youxian gongsi, 2003.

11. While discussing the chapter on "Marriage Life" in her book Tongxinglian yawenhua, Li Yinhe argued that "the biggest difference between the Chinese male homosexuals and their Western counterparts is that, in the West, only $1 / 5$ of male homosexuals were married. Based on our survey, however, some are already married, some are going to get married, and only a handful of gay men are not going to marry". Li states the most important reason for Chinese gay men to get married, although all are reluctant to marry, is the pressure of Chinese culture and norms, which emphasise marriage and family values.

12. Lisa Rofel, "Qualities of Desire : Imagining Gay Identities in China", GLQ $5: 4$, pp. 451-474.

13. Vivienne Cass, “Homosexual Identity Formation : Testing a Theoretical Model”, Journal of Sex Research, 20, 1996, pp. 147-167.

14. Eve Kosovsky Sedgewick, Epistemology of the Closet, Los Angeles, University of California Press, 1990.

15. Vivienne Cass, « Homosexual Identity Formation : A Theoretical Model », Journal of Homosexuality, 4, 1979, pp. 219-235.

16. Wong, Chi-yan, and Catherine So-kum Tang, "Sexual Practices and Psychosocial Correlates of Current Condom Use Among Chinese Gay Men in Hong Kong", Archives of Sexual Behavior, Vol. 33, No. 2, April 2004, pp. 159-167.

17. Valerian J. Derlega, Gust A. Yep, Sandra Petronio, Kathryn Greene (eds.), Self Disclosure, Newbury Park, Ca., Sage, 1993. 
18. Wong, Chi-yan, and Catherine So-kum Tang, "Coming Out Experiences and Psychological Distress of Homosexual Men in Hong Kong", Archives of Sexual Behavior, Vol. 33, No. 2, April 2004, pp. 149-157.

19. Lisa Rofel, op. cit., pp. 451-474.

20. Travis S.K. Kong, The Hidden Voice : The Sexual Politics of Chinese Male Sex Workers, Hong Kong, Centre for Social Policy Studies, Department of Applied Social Sciences, The Hong Kong Polytechnic University, 2005, p. 32.

21. A study of sexual orientation by Alan Bell, Martin Weinberg, and Sue Hammersmith, of the Kinsey Institute (1981) indicates that sexual orientation seems to be determined before adolescence, a finding supported here. Li Yinhe finds range of ages of sexual identity recognition, ranging from 14 to 29. See Li Yinhe, Li Yinhe, op. cit., p. 39.

22. Vivienne Cass, "Homosexual Identity Formation : A Theoretical model", op. cit.

23. Wong Chi-yan, and Catherine So-kum Tang, "Coming Out Experiences and Psychological Distress of Homosexual Men in Hong Kong", op. cit.

24. James Farrer, op. cit.

\section{ABSTRACTS}

Chinese men who have sex with men are increasingly aware of public discourses of homosexuality, and have created numerous public spaces in which they can make contact with other Chinese men who have sex with men (MSM). At the same time Chinese in general, as well as MSM themselves, have increasingly also become aware of models of openly tolerated "gay", "homosexual" or "tongzhi" identities popularised through the media, especially internet media. Therefore MSM in large Chinese cities now seem to have a greater number of possible models of sexual identification than in the past, as well as a more tolerant atmosphere for revealing their sexual identities in various social contexts. This paper uses in depth interviews with 30 MSM in Shanghai to discover how they construct and organise their social identities as MSM. It examines the terms men use to describe their sexual orientation, including the nuances that accrue to these terms, stories of how men come to identify themselves as MSM, gay or tongzhi, including their assessment of their sexual orientation, and their different patterns of revealing their sexual identities to different members of their social circles. In particular, it looks at some of the sociological factors that seem to influence self-revelation outside the gay circle, also the consequences of these patterns of self revelation and concealment for these other types of social relations. 